\title{
Prognosis and clinical characteristics of patients with early ventricular fibrillation in the 6-week guideline-offered time period: is it safe to wait 6 weeks with the assessment? (results from the VMAJOR-MI Registry)
}

\author{
Réka Skoda ${ }^{1}$, Attila Nemes ${ }^{1,2}$, György Bárczi ${ }^{1}$, József Gajdácsi ${ }^{1}$, Hajnalka Vágó ${ }^{1}$, Zoltán Ruzsa ${ }^{1}$, István F. \\ Édes $^{1}$, Liliána Szabó$^{1}$, Csilla Czimbalmos ${ }^{1}$, Nóra Sydó ${ }^{1}$, Elek Dinya ${ }^{1}$, Béla Merkely ${ }^{1}$, Dávid Becker ${ }^{1}$ \\ ${ }^{1}$ Heart and Vascular Center, Semmelweis University, Budapest, Hungary; ${ }^{2}$ Department of Medicine, Albert Szent-Györgyi Clinical Center, Medical \\ Faculty, University of Szeged, Szeged, Hungary
}

Correspondence to: Dávid Becker, MD, PhD, FESC. Városmajor U. 68, Budapest, 1122 Hungary. Email: becker.david@kardio.sote.hu.

\begin{abstract}
Background: The most common, potentially fatal complication following an acute myocardial infarction (AMI) is early ventricular fibrillation (EVF). According to the guidelines, the assessment of implanting an implantable cardioverter defibrillator (ICD) is sufficient 6 weeks after the event, in patients with reduced left ventricular ejection fraction (LVEF), regardless of VF. The present study aimed to evaluate the 6-week prognosis of patients surviving an EVF. We divided the patients in two group based on their general condition at the time they left the hospital. We investigated the clinical characteristics of patients discharged in good general health but still dying within 6 weeks.
\end{abstract}

Methods: The present study comprised 12,270 patients with AMI following their primary revascularization in the first $12 \mathrm{~h}$ of symptom onset. Five hundred and forty-seven of them suffered EVF due to the AMI. Clinical and 6-week mortality data were examined.

Results: Poor general condition correlates with multiple comorbidities, higher troponin levels, more severe complications after the event. Patients leaving in good condition thought to be low risk, from dying. But low LVEF, high blood sugar, high cardiac biomarker level, poor renal function elevates the risk of dying within 6 weeks. However, there is no difference in clinical characteristics between EVF- cases and EVF+ cases in good condition who dies within 6 weeks.

Conclusions: According to our study we can select patients who are safe in the critical 6-week period and those who need closer follow-up despite leaving in good general condition.

Keywords: Early ventricular fibrillation (EVF); acute myocardial infarction (AMI); prognosis

Submitted Aug 14, 2020. Accepted for publication Sep 11, 2020.

doi: 10.21037/qims-20-973

View this article at: http://dx.doi.org/10.21037/qims-20-973

\section{Introduction}

The most common early lethal complication is an early ventricular fibrillation (EVF) following acute coronary syndrome (ACS) or acute myocardial infarction (AMI) $(1,2)$. Ventricular arrhythmias occur in $80-85 \%$ within 48 hours after the event. Early or primary ventricular fibrillation (PVF) develops in 48-72 hours after the start of the myocardial infarction (MI) symptoms and has no relationship to any recurrent ischaemia or heart failure.

The rate of death, including sudden cardiac death (SCD) is the highest in the early phase after a MI. There is no special guidance, how to treat MI patients suffering EVF, no protocol about their secondary prevention, among others early implantable cardioverter defibrillator (ICD) implantation. Current guidelines do not suggest prevention of SCD within 
40 days (3). According to the guidelines, ICD therapy is recommended to prevent SCD for patients with symptomatic heart failure (NYHA Class II-III) and left ventricular ejection fraction (LVEF) $\leq 35 \%$ despite optimal medical therapy but just 6 weeks past the event. Earlier ( $<40$ days) ICD implantation or the use of wearable cardioverter defibrillator may be considered in a selected patient groupincomplete revascularization, pre-existing LVEF dysfunction or occurrence of malignant arrhythmias 48 hours after STsegment elevation MI (STEMI) $(1,4)$. However, there are conflicting results regarding the prognosis of EVF survivors $(2,5)$. EVF has a significant effect on in-hospital mortality (6). Even in the percutaneous coronary intervention (PCI), PCIera, acute phase of ventricular tachyarrhythmia (VT) or ventricular fibrillation (VF) was associated with higher inhospital mortality in case of STEMI (7). Solomon et al. found that the risk of SCD is the highest within 30 days after the $\mathrm{MI}$ in patients with reduced $\mathrm{EF}$ or heart failure. The rate of SCD is $1.4 \%$ in the first month, and $0.14 \%$ in 2 years (8). On the other hand there are results suggesting that prophylactic ICD therapy does not reduce overall mortality (3), not even in high-risk patients but was associated with reduction of death due to arrhythmia (9).

In a high-volume, modern PCI-centrum, in order to be able to manage the great number of patients, after couple of days they are either discharged home, to a rehabilitation facility or transferred to another hospital for further evaluation.

The present study was designed to assess the survival of MI patients with EVF after the guideline recommended 6-week time period. It is evident that the patients' general condition has an effect on the prognosis. But there is no data whether it is safe to wait 6 weeks with the decision. There may be a high-risk patient group that would benefit from an early judgment and more specialised treatment at a cardiac centrum. In order to find the clinical characteristics of the high-risk patients, we aimed to examine whether the general condition of the patients at discharge has any relation to the prognosis.

\section{Methods}

\section{Patient population, data collection}

A total of 11,582 patients with ACS have been revascularised between 2005 and 2013 at our Institution. These consecutive patients were enrolled to a registry, named Városmajor Myocardial Infarction Registry (VMAJOR-MI Registry), in which all the available demographic (gender, date of birth, date of admission, date of death) and clinical patient data-laboratory findings [troponin $\mathrm{T}$, creatine kinase-MB (CK-MB), creatinine, glucose, cholesterol, lowdensity lipoprotein (LDL)-cholesterol], type of infarction [STEMI, non-STEMI (NSTEMI)]-results from echocardiography (LVEF), coronary angiography-have been summarised. The acute event has been characterised by its severity-complicated by EVF, cardiogenic shock, on site resuscitation - and by its complications-heart failure, invasive respiratory treatment. EVF-positive patients' data has been supplemented by the following factors: laboratory parameters [potassium, white blood cell (WBC) count, C-reactive protein (CRP)], detailed coronary-status (number of vessels affected, number of vessels treated by PCI).

Two groups were created based on the fact that AMI was complicated by EVF or not. VF requiring defibrillation in the first 48 hours of the peri-hospital period was used as a definition of EVF. Other types of ventricular arrhythmias, such as ventricular tachycardia was not examined. Patient group with EVF was further divided regarding their general condition (good vs. poor). We evaluated the patients' clinical characteristics at discharge. Patients who were released home or to a cardiac rehabilitation facility and did not require further in-patient cardiac care (no heart failure, no recurrent malignant arrhythmia) created the good general condition patient group. To the poor general condition group, we enrolled patients who died at our institution or were transferred to another department on invasive respiratory treatment or needed further in-patient cardiac care because of heart failure, arrhythmias or any other even non-cardiac reasons.

Only patients with primary revascularization were included into the study which was defined as PCI in the first $12 \mathrm{~h}$ of symptom onset (10). Patients undergoing coronary artery bypass grafting surgery were not eligible for the study, as well as we excluded those who were managed conservatively. Coronary stenosis was evaluated from multiplane projections and a luminal diameter reduction of $>50 \%$ was considered significant.

The study protocol conformed to the ethical guidelines of the 1975 Declaration of Helsinki and was approved in advance by the locally appointed ethics committee (30088-2/2014/ EKU). The primary outcome of the study was all-cause mortality. The National Health Care Institute provided the accurate details on the above endpoint with occurrence dates.

\section{Statistical methods}

The analysis was performed using Statistica 13.2 statistical 
Table 1 Differences in clinical parameters according to the general condition of patients with early ventricular fibrillation

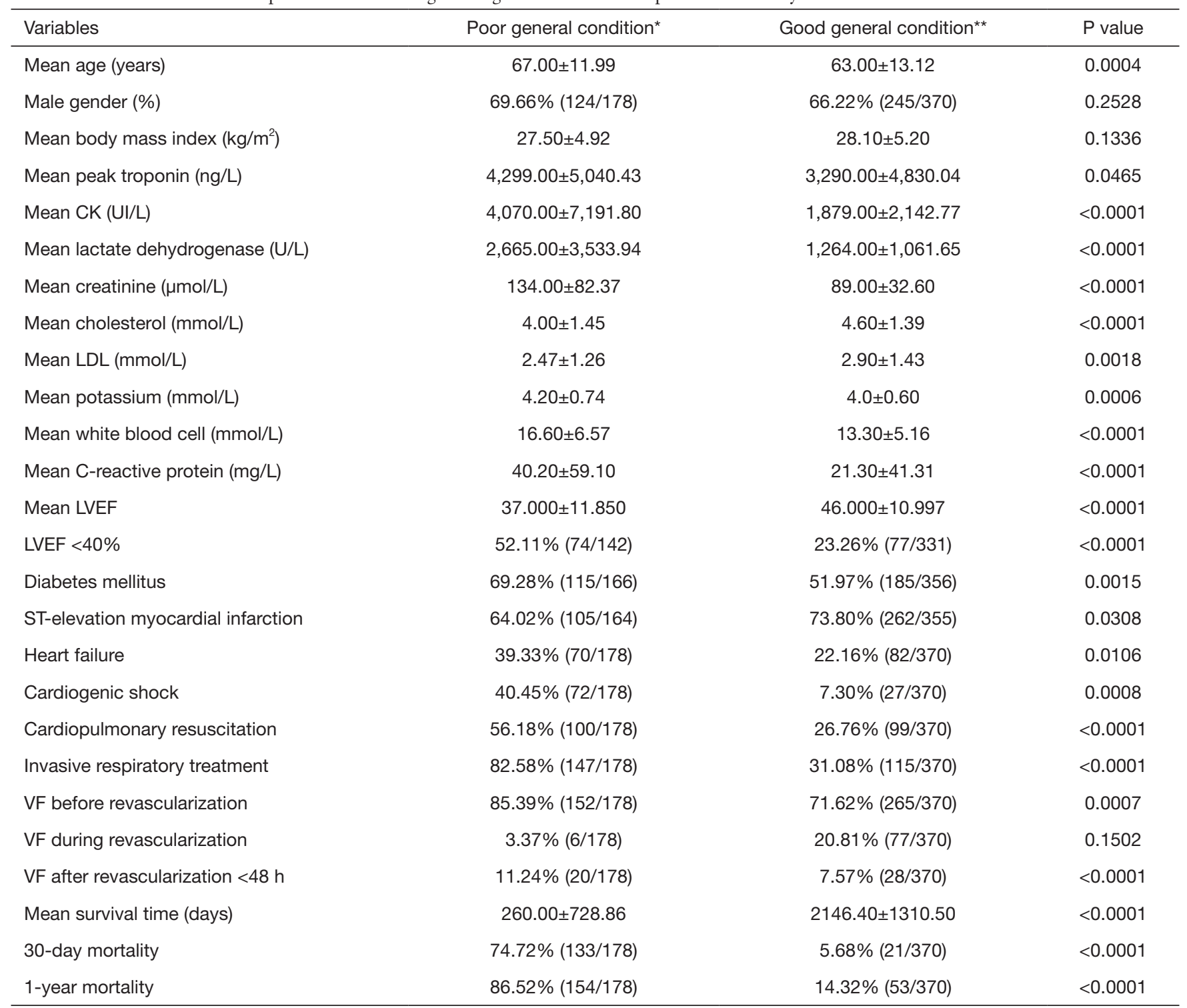

*, patients who died at our institution or were transferred to another department on invasive respiratory treatment or needed further inpatient cardiac care; ${ }^{*}$, patients who were released home or to a cardiac rehabilitation facility and did not require further in-patient cardiac care. CK, creatine kinase; LDL, low-density lipoprotein; LVEF, left ventricular ejection fraction; VF, ventricular fibrillation.

software. Continuous variables were expressed as mean and standard deviation (mean $\pm \mathrm{SD}$ ), categorical variables were summarized as sample size (n) and frequencies. For assessment of normality of distribution, Shapiro-Wilks test was used. Levene's test was used to evaluate homogeneity of variances. Student's $t$-test was used for comparison of normally distributed data and Mann-Whitney $U$ test for not normally distributed data. Categorical variables were compared using Chi-square test. For offline data analysis and graph creation a commercial software package was used (Microsoft Excel 2016).

\section{Results}

The clinical characteristics of the potentially high-risk patients in poor general condition has been compared to the assumed low-risk good general condition patient group. Detailed results are presented in Table 1. Those in poor 
Table 2 The impact of the extent of disease and its invasive treatment on 6-week mortality based on the general condition of patients with early ventricular fibrillation

\begin{tabular}{lllll}
\hline $\begin{array}{l}\text { Coronary angiography } \\
\text { results }\end{array}$ & Total & Dead & $\%$ & P value \\
\hline
\end{tabular}

Poor general condition*

CA

$\begin{array}{lcccc}\text { 1-vessel disease } & 69 & 49 & 71.01 & - \\ \text { 2-vessel disease } & 45 & 35 & 77.78 & 0.2432 \\ \text { 3-vessel disease } & 43 & 40 & 93.02 & 0.0043 \\ \text { LM included } & 20 & 15 & 75.00 & 0.3817 \\ \text { PCI } & & & & \\ \text { On 1 vessel } & 111 & 83 & 74.77 & - \\ \text { On 2 vessels } & 35 & 30 & 85.71 & 0.1087 \\ \text { On 3 vessels } & 8 & 7 & 87.50 & 0.2252 \\ \text { Not performed } & 24 & 20 & 83.33 & 0.2091\end{array}$

Good general condition**

CA

$\begin{array}{lcccc}\text { 1-vessel disease } & 193 & 8 & 4.15 & - \\ \text { 2-vessel disease } & 105 & 6 & 5.71 & 0.4464 \\ \text { 3-vessel disease } & 55 & 9 & 16.36 & 0.2073 \\ \text { LM included } & 15 & 2 & 13.33 & 0.3122 \\ \text { PCI } & & & & \\ \text { On 1 vessel } & 302 & 15 & 4.97 & - \\ \text { On 2 vessels } & 34 & 5 & 14.71 & 0.2357 \\ \text { On 3 vessels } & 6 & 0 & 0 & - \\ \text { Not performed } & 27 & 5 & 18.52 & 0.1715\end{array}$

*, patients who died at our institution or were transferred to another department on invasive respiratory treatment or needed further in-patient cardiac care; ${ }^{* *}$, patients who were released home or to a cardiac rehabilitation facility and did not require further in-patient cardiac care. CA, coronary angiography; $\mathrm{LM}$, left main coronary artery; $\mathrm{PCI}$, percutaneous coronary intervention.

condition were older (67 vs. 63 years, $\mathrm{P}=0.0004)$, more likely to have diabetes $(69.28 \%$ vs. $51.97 \%, \mathrm{P}=0.0015)$, reduced left ventricle and kidney function. They had higher cardiac biomarker, peak troponin $\mathrm{T}$ levels (4,299 vs. 3,290 $\mathrm{ng} / \mathrm{L}, \mathrm{P}=0.0465)$, higher lactate dehydrogenase (LDH) levels (2,665 vs. 1,264 U/L) meaning more necrosis, larger infarct size. Inflammatory parameters were elevated as well, CRP (40.20 vs. $21.30 \mathrm{mg} / \mathrm{L}, \mathrm{P}<0.0001)$, WBC count (16.60 vs. $13.30 \mathrm{mmol} / \mathrm{L}, \mathrm{P}<0.0001)$. The acute event was more severe: heart failure (39.33\% vs. $22.16 \%, \mathrm{P}=0.0106)$, cardiogenic shock $(40.45 \%$ vs. $7.30 \%, \mathrm{P}=0.0008)$.

The impact of the extent of the disease and its invasive treatment on 6-week mortality based on the general condition of the patients is presented in Table 2. Threevessel disease complicated with poor condition was associated with higher 6-week mortality $(93.02 \%, 40 / 43$; $\mathrm{P}=0.0043)$. The extent of the coronary artery disease (CAD) had no impact on mortality in patients with good condition.

There were 25 patients discharged in good condition who died within 6 weeks. Comparing their clinical data to those who survived, the following factors were found to be significant: mean age ( 74 vs. 62 years, $\mathrm{P}=0.0119)$, diabetes (83.33\% vs. $49.70 \%, \mathrm{P}=0.0022)$, mean troponin $\mathrm{T}(5,764$ vs. $3,137 \mathrm{ng} / \mathrm{L}, \mathrm{P}=0.0161$ ), LVEF $<40 \%$ (59.09\% vs. $21.71 \%$, $\mathrm{P}=0.0023)$, more severe acute event-heart failure $(52.00 \%$ vs. $20.00 \%, \mathrm{P}=0.0073)$, invasive respiratory treatment ( $72.00 \%$ vs. $28.12 \%, \mathrm{P}=0.0002)$. Full analysis is presented in Table 3. Differences between EVF-negative patients dying within 6 weeks $v s$. EVF-positive patients in good general condition dying within 6 weeks is shown in Table 4. Besides diabetes, there was no significant difference between the two groups.

Our results are based on a registry in which the data of the index ACS has been collected between 2005 and 2013. We use this database as background for long-term follow-up. This timeframe does not affect the results, since the guidelines and the policy of our institute about revascularisation have not change.

\section{Discussion}

Following AMI there is an increased risk of SCD, especially showing reduced LVEF $(<40 \%)$ or frequent ventricular premature beats (VPBs). In high-risk post-MI patients, the risk of arrhythmic death (AD) is higher for up to 2 years. However, risk stratification for ICD would be optimal in the first 6 months, noticing that the chance for both arrhythmic and non-AD is the highest within 6 months (11). Theoretically, ICD implantation following AMI and revascularization would save lives due to presence of higher SCD incidence (12). Although ICD implantation for both secondary and primary prevention has been shown reducing all-cause mortality, DINAMIT and IRIS trials demonstrated that early ICD implantation within 40 days does not reduce mortality in high-risk post-MI patients. 
Table 3 Differences in clinical parameters of patients leaving institution in good general shape but dying within six weeks vs. survivors

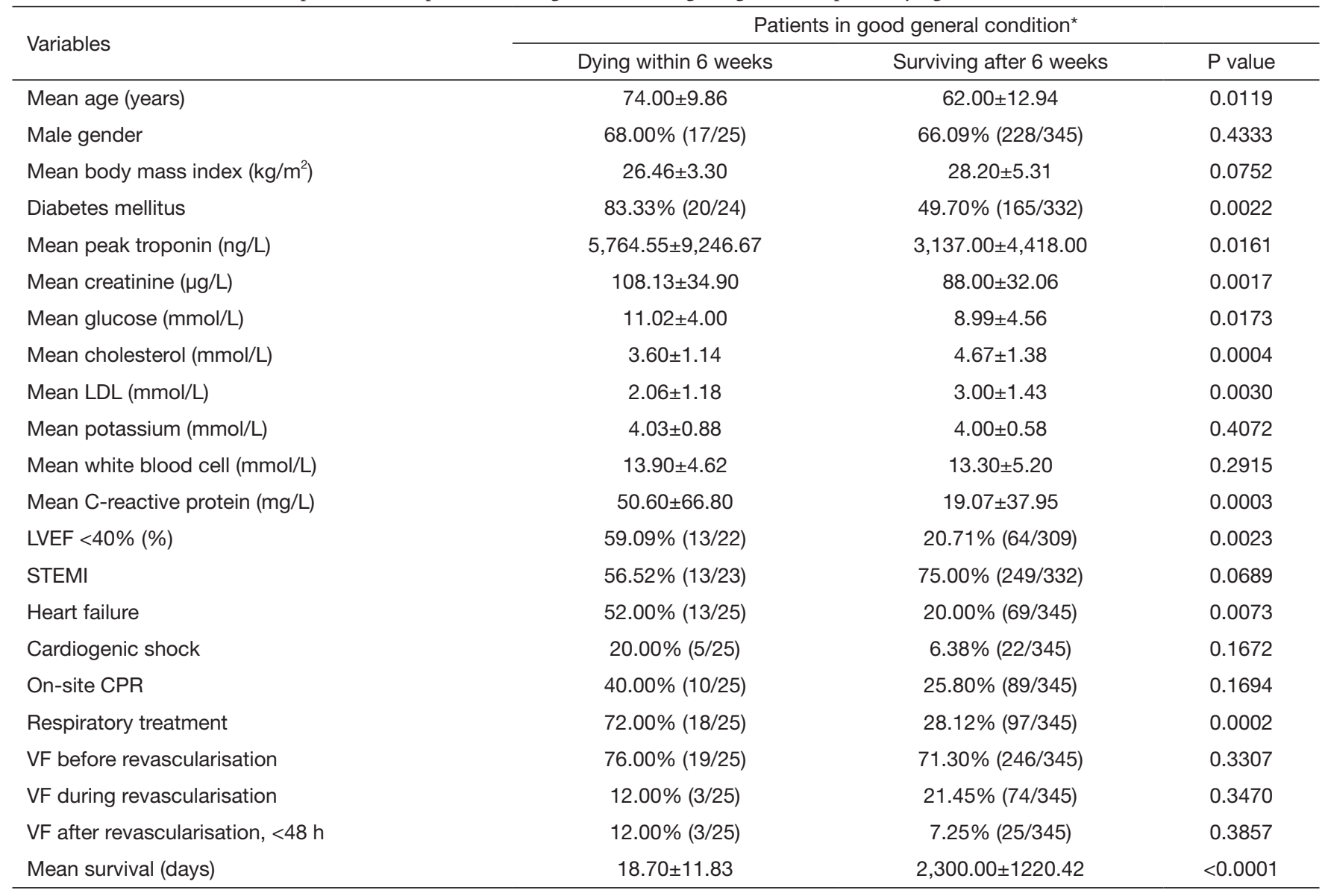

*, patients who were released home or to a cardiac rehabilitation facility and did not require further in-patient cardiac care. CPR, cardiopulmonary resuscitation; LDL, low-density lipoprotein; LVEF, left ventricular ejection fraction; STEMI, ST-elevation myocardial infarction; VF, ventricular fibrillation.

Table 4 Clinical characteristics of patients dying within 6 weeks. Comparison of patients' data having early ventricular fibrillation and leaving the hospital in good general condition and patients not having early ventricular fibrillation

\begin{tabular}{|c|c|c|c|}
\hline \multirow{2}{*}{ Characteristics } & \multicolumn{2}{|c|}{ Patients dying within 6 weeks } & \multirow{2}{*}{$P$ value } \\
\hline & Good general condition and VF+ & VF- & \\
\hline All cases & $6.76 \%(25 / 370)$ & $7.88 \%(902 / 11,440)$ & 0.4143 \\
\hline Male gender & $68.00 \%(17 / 25)$ & $53.88 \%(486 / 902)$ & 0.1253 \\
\hline NSTEMI & $43.48 \%(10 / 23)$ & $54.53 \%(469 / 860)$ & 0.2438 \\
\hline DM & $83.33 \%(20 / 24)$ & $63.84 \%(535 / 838)$ & 0.0368 \\
\hline Creatinine $<100(\mu \mathrm{mol} / \mathrm{L})$ & $50.00 \%(12 / 24)$ & $60.00 \%(513 / 855)$ & 0.2425 \\
\hline Cardiogenic shock & $20.00 \%(5 / 25)$ & $29.82 \%(269 / 902)$ & 0.3169 \\
\hline On site CPR & $40.00 \%(10 / 25)$ & $5.99 \%(54 / 902)$ & 0.0009 \\
\hline
\end{tabular}

CPR, cardiopulmonary resuscitation; DM, diabetes mellitus; LVEF, left ventricular ejection fraction; NSTEMI, non-ST-elevation myocardial infarction; VF, ventricular fibrillation. 
These findings could be explained by the increase in death due to non-arrhythmic causes (e.g., heart failure, free wall rupture etc.) $(3,9)$. Based on these results ICD implantation for primary prevention in post-MI patients is recommended later than 40 days $(1,13)$. In AMI, the incidence of ventricular arrhythmias including EVF is about $2-8 \%(1,2)$. However, results according to its significance on prognosis is controversial. Masuda et al. stated that acute phase VT/VF associated with in hospital mortality even in the PCI era, moreover with increased 5-year mortality in high-risk patients (GRACE Risk Score >115) (7). In the era of routine primary PCI era in STEMI although overall STEMI mortality declined, PVF remained as predictor for 30-day and 1-year mortality (14). Results from the database of APEX-AMI trial showed increased 90-day mortality in patients with VT/VF presenting for primary PCI (15). On the other hand the prospective GISSI-2 trial revealed that both early ( $<4 \mathrm{~h}$ ) and late (4-48 h) PVF was an independent risk factor for in hospital death but post-discharge to 6 months prognosis was unaffected (16). Other studies found similar results, EVF had significant effect only on in-hospital mortality $(6,17)$. High short-term survival was detected by STEMI patients undergoing PCI and receiving drug eluting stents (18).

Seeing these conflicting results about the post-discharge prognosis of EVF patients, comparing patients based on their general condition at discharge had the following result. Higher age, larger infarct size-meaning higher biomarker levels (troponin T, CK), higher $\mathrm{LDH}$, inflammation (WBC count, CRP levels), more comorbidities (diabetes, poor renal function), more severe acute event resulting in cardiogenic shock, heart failure correlates with poor general condition. These patients had significantly lower mean survival time, high $75 \%$ short-term, 30-day and high $86.5 \%$ long-term, 1 -year mortality. Being sad that they remain a high-risk patient group who would benefit at least from a closer follow-up in the 6-week time-period recommended by the guidelines. Gheeraert et al. found that out of hospital VF in patients with AMI has angiographic determinants (19). Considering that the amount of myocardium at risk may have an effect on prognosis, we found that the extent of the $\mathrm{CAD}$ resulted in higher 6-week mortality only in highrisk patients, in the poor general condition patient group. Mortality and the extent of the disease in patients with good general condition were not related. The technological impact of advances on PCI revascularization has not affected our results, being sad that our institute's invasive approach has always been high. PCI rates in NSTEMI patients with EVF
$(81 \%, 122 / 151)$ exceeded percentage seen in literature (20).

We could select those patients in good general condition who have low mortality risk in the critical 6-week periodbefore they are assessed whether to get an ICD or not. However, age, diabetes, reduced LVEF, larger infarct size (higher troponin level), NSTEMI, reduced kidney function count as risk factors for dying within 6 weeks in spite of the good general condition. Overall comparing 6-week mortality characteristics of EVF- patients to EVF + cases in good condition, there is no significant difference between the two groups.

The general condition of the patients at discharge influence the prognosis. Patients with poor general condition and those in good general condition but having NSTEMI, reduced LVEF may benefit from a closer follow up at a high volume invasive cardiac centrum employing telemedicine devices. In assorted cases earlier ICD implantation would be beneficial. In conclusion, it is safe to say that there is a low risk of dying within the 6-week time period offering by the guidelines.

\section{Limitation section}

The most important limitation is that the present study was a retrospective observational study with its special limitations. Factors affecting the prognosis such as medication intake, compliance could not be investigated.

\section{Acknowledgments}

Funding: None.

\section{Footnote}

Conflicts of Interest: All authors have completed the ICMJE uniform disclosure form (available at http://dx.doi. org/10.21037/qims-20-973). AN serves as an unpaid editorial board member of Quantitative Imaging in Medicine and Surgery. The other authors have no conflicts of interest to declare.

Ethical Statement: The study protocol conformed to the ethical guidelines of the 1975 Declaration of Helsinki and was approved in advance by the locally appointed ethics committee (30088-2/2014/EKU).

Open Access Statement: This is an Open Access article distributed in accordance with the Creative Commons 
Attribution-NonCommercial-NoDerivs 4.0 International License (CC BY-NC-ND 4.0), which permits the noncommercial replication and distribution of the article with the strict proviso that no changes or edits are made and the original work is properly cited (including links to both the formal publication through the relevant DOI and the license). See: https://creativecommons.org/licenses/by-nc-nd/4.0/.

\section{References}

1. Zipes DP, Camm AJ, Borggrefe M, Buxton AE, Chaitman B, Fromer M, Gregoratos G, Klein G, Moss AJ, Myerburg RJ, Priori SG, Quinones MA, Roden DM, Silka MJ, Tracy C, Smith SC Jr, Jacobs AK, Adams CD, Antman EM, Anderson JL, Hunt SA, Halperin JL, Nishimura R, Ornato JP, Page RL, Riegel B, Blanc JJ, Budaj A, Dean V, Deckers JW, Despres C, Dickstein K, Lekakis J, McGregor K, Metra M, Morais J, Osterspey A, Tamargo JL, Zamorano JL. ACC/AHA/ESC 2006 Guidelines for Management of Patients With Ventricular Arrhythmias and the Prevention of Sudden Cardiac Death: a report of the American College of Cardiology/American Heart Association Task Force and the European Society of Cardiology Committee for Practice Guidelines (writing committee to develop Guidelines for Management of Patients With Ventricular Arrhythmias and the Prevention of Sudden Cardiac Death): developed in collaboration with the European Heart Rhythm Association and the Heart Rhythm Society. Circulation 2006;114:e385-484.

2. Medina-Rodríguez KE, Almendro-Delia M, GarcíaAlcántara Á, Arias-Garrido JJ, Rodríguez-Yáñez JC, Alonso-Muñoz G, de la Chica-Ruiz-Ruano R, Reina-Toral A, Varela-López A, Arboleda-Sánchez JA, Poullet-Brea AM, Zaya-Ganfo B, Butrón-Calderón M, Cristo-Ropero MJ, Hidalgo-Urbano R, García-Rubira JC. Prognostic implication of early ventricular fibrillation among patients with ST elevation myocardial infarction. Coron Artery Dis 2017;28:570-6.

3. Steinbeck G, Andresen D, Seidl K, Brachmann J, Hoffmann E, Wojciechowski D, Kornacewicz-Jach Z, Sredniawa B, Lupkovics G, Hofgärtner F, Lubinski A, Rosenquist M, Habets A, Wegscheider K, Senges J. Defibrillator implantation early after myocardial infarction. N Engl J Med 2009;361:1427-36.

4. Priori SG, Blomström-Lundqvist C, Mazzanti A, Blom N, Borggrefe M, Camm J, Elliott PM, Fitzsimons D, Hatala R, Hindricks G, Kirchhof P, Kjeldsen K, Kuck KH, Hernandez-Madrid A, Nikolaou N, Norekvål TM,
Spaulding C, Van Veldhuisen DJ. 2015 ESC Guidelines for the management of patients with ventricular arrhythmias and the prevention of sudden cardiac death: The Task Force for the Management of Patients with Ventricular Arrhythmias and the Prevention of Sudden Cardiac Death of the European Society of Cardiology (ESC). Endorsed by: Association for European Paediatric and Congenital Cardiology (AEPC). Eur Heart J 2015;36:2793-867.

5. O'Doherty M, Tayler DI, Quinn E, Vincent R, Chamberlain DA. Five hundred patients with myocardial infarction monitored within one hour of symptoms. $\mathrm{Br}$ Med J (Clin Res Ed) 1983;286:1405-8.

6. Behar S, Goldbourt U, Reicher-Reiss H, Kaplinsky E. Prognosis of acute myocardial infarction complicated by primary ventricular fibrillation. Principal Investigators of the SPRINT Study. Am J Cardiol 1990;66:1208-11.

7. Masuda $M$, Nakatani D, Hikoso S, Suna S, Usami $M$, Matsumoto S, Kitamura T, Minamiguchi H, Okuyama Y, Uematsu M, Yamada T, Iwakura K, Hamasaki T, Sakata Y, Sato H, Nanto S, Hori M, Komuro I. Clinical Impact of Ventricular Tachycardia and/or Fibrillation During the Acute Phase of Acute Myocardial Infarction on InHospital and 5-Year Mortality Rates in the Percutaneous Coronary Intervention Era. Circ J 2016;80:1539-47.

8. Solomon SD, Zelenkofske S, McMurray JJ, Finn PV, Velazquez E, Ertl G, Harsanyi A, Rouleau JL, Maggioni A, Kober L, White H, Van de Werf F, Pieper K, Califf RM, Pfeffer MA. Sudden death in patients with myocardial infarction and left ventricular dysfunction, heart failure, or both. N Engl J Med 2005;352:2581-8.

9. Hohnloser SH, Kuck KH, Dorian P, Roberts RS, Hampton JR, Hatala R, Fain E, Gent M, Connolly SJ. Prophylactic use of an implantable cardioverter-defibrillator after acute myocardial infarction. N Engl J Med 2004;351:2481-8.

10. Neumann FJ, Sousa-Uva M, Ahlsson A, Alfonso F, Banning AP, Benedetto U, Byrne RA, Collet JP, Falk V, Head SJ, Jüni P, Kastrati A, Koller A, Kristensen SD, Niebauer J, Richter DJ, Seferovic PM, Sibbing D, Stefanini GG, Windecker S, Yadav R, Zembala MO. 2018 ESC/EACTS Guidelines on myocardial revascularization. Eur Heart J 2019;40:87-165.

11. Yap YG, Duong T, Bland M, Malik M, Torp-Pedersen C, Køber L, Connolly SJ, Marchant B, Camm J. Temporal trends on the risk of arrhythmic vs. non-arrhythmic deaths in high-risk patients after myocardial infarction: a combined analysis from multicentre trials. Eur Heart J 2005;26:1385-93.

12. Buxton AE, Lee KL, Fisher JD, Josephson ME, 
Prystowsky EN, Hafley G. A randomized study of the prevention of sudden death in patients with coronary artery disease. Multicenter Unsustained Tachycardia Trial Investigators. N Engl J Med 1999;341:1882-90.

13. Hunt SA, Abraham WT, Chin MH, Feldman AM, Francis GS, Ganiats TG, Jessup M, Konstam MA, Mancini DM, Michl K, Oates JA, Rahko PS, Silver MA, Stevenson LW, Yancy CW, Antman EM, Smith SC Jr, Adams CD, Anderson JL, Faxon DP, Fuster V, Halperin JL, Hiratzka LF, Jacobs AK, Nishimura R, Ornato JP, Page RL, Riegel B. ACC/AHA 2005 Guideline Update for the Diagnosis and Management of Chronic Heart Failure in the Adult: a report of the American College of Cardiology/American Heart Association Task Force on Practice Guidelines (Writing Committee to Update the 2001 Guidelines for the Evaluation and Management of Heart Failure): developed in collaboration with the American College of Chest Physicians and the International Society for Heart and Lung Transplantation: endorsed by the Heart Rhythm Society. Circulation 2005;112:e154-235.

14. García-García C, Oliveras T, Rueda F, Pérez-Fernández S, Ferrer M, Serra J, Labata C, Vila J, Carrillo X, RodríguezLeor O, Fernández-Nofrerias E, Faixedas MT, Jiménez J, Mauri J, Lupón J, Bayes-Genis A. Primary Ventricular Fibrillation in the Primary Percutaneous Coronary Intervention ST-Segment Elevation Myocardial Infarction Era (from the "Codi IAM" Multicenter Registry). Am J Cardiol 2018;122:529-36.

15. Mehta RH, Starr AZ, Lopes RD, Hochman JS, Widimsky P, Pieper KS, Armstrong PW, Granger CB. Incidence of and outcomes associated with ventricular tachycardia or fibrillation in patients undergoing primary percutaneous coronary intervention. JAMA 2009;301:1779-89.

Cite this article as: Skoda R, Nemes A, Bárczi G, Gajdácsi J, Vágó H, Ruzsa Z, Édes IF, Szabó L, Czimbalmos C, Sydó N, Dinya E, Merkely B, Becker D. Prognosis and clinical characteristics of patients with early ventricular fibrillation in the 6-week guideline-offered time period: is it safe to wait 6 weeks with the assessment? (results from the VMAJORMI Registry). Quant Imaging Med Surg 2021;11(1):402-409. doi: 10.21037/qims-20-973
16. Volpi A, Cavalli A, Santoro L, Negri E. Incidence and prognosis of early primary ventricular fibrillation in acute myocardial infarction--results of the Gruppo Italiano per lo Studio della Sopravvivenza nell'Infarto Miocardico (GISSI-2) database. Am J Cardiol 1998;82:265-71.

17. Tofler GH, Stone PH, Muller JE, Rutherford JD, Willich SN, Gustafson NF, Poole WK, Sobel BE, Willerson JT, Robertson T, Passamani E, Braunwald E; MILIS Study Group. Prognosis after cardiac arrest due to ventricular tachycardia or ventricular fibrillation associated with acute myocardial infarction (the MILIS Study). Multicenter Investigation of the Limitation of Infarct Size. Am J Cardiol 1987;60:755-61.

18. Zareh M, Rade JJ, Thomas JL, Shah A, Chhabra A, Prutkin J, Shinar Z, Abraham M, Deal N, Kuo D, Pearson D, Garvey L, Lange D, Henry TD, Desai S, Kim H, Swadron S, Tun H, Shavelle DM. ST-Segment Elevation Myocardial Infarction and Out-of-Hospital Cardiac Arrest: Contemporary Management From the Multicenter START Registry. J Invasive Cardiol 2020;32:104-9.

19. Gheeraert PJ, Henriques JP, De Buyzere ML, Voet J, Calle P, Taeymans Y, Zijlstra F. Out-of-hospital ventricular fibrillation in patients with acute myocardial infarction: coronary angiographic determinants. J Am Coll Cardiol 2000;35:144-50.

20. Patel N, Patel NJ, Macon CJ, Thakkar B, Desai M, Rengifo-Moreno P, Alfonso CE, Myerburg RJ, Bhatt DL, Cohen MG. Trends and Outcomes of Coronary Angiography and Percutaneous Coronary Intervention After Out-of-Hospital Cardiac Arrest Associated With Ventricular Fibrillation or Pulseless Ventricular Tachycardia. JAMA Cardiol 2016;1:890-9. 